\title{
Prepared polyclonal antibody of the semicarbazide
}

\author{
Xuan-yun HUANG ${ }^{1, a}$, Dong-mei HUANG $^{1, b}$, You-qiong CAI ${ }^{1, \mathrm{c} *}$
}

1. East China Sea Fisheries Research Institute, CAFS Aquatic Product Quality Inspection and Test Center (Shanghai), Ministry of Agriculture of PR China, Shanghai 200090, PR China

a Hxyseven@163.com, ${ }^{\mathrm{b}} \mathrm{Hdm} 2001 @ 126 . c o m,{ }^{\mathrm{c}}$ 'Caiyouqiong@163.com

Keywords: Nitrofurazone ;Semicarbazide; Hapten; Conjuguate; Polyclonal Antibody

Abstract: Nitrofurazone residues in fishery products were dangerous for human health, semicarbazide (SEM) was the nitrofurazone metabolite could residues in fishery in a long time . To detect SEM residues in fishery products rapidly by immune method, preparation of high quality polyclonal antibody against SEM was the most critical step of project. We produced two kinds of antigens for SEM, using carrier protein bovine serum albumin (BSA) and ovalbumin (OVA) by a modified carbodiimide method, and then the hapten-protein conjugates were characterized by ultraviolet spectrophotometry in detecting qualitatively comparable hapten density, before being used for the immunization and detection purposes. The production of polyclonal antibodies (PcAbs) were sought following the generation of appropriate SEM-BSA conjugate. One PcAb against Semicarbazide (SEM) was produced and the titer polyclonal antibody could reach $10^{5}$. In the optimized ELISA, the PcAb showed $50 \%$ inhibition at $25.0 \mathrm{ng} / \mathrm{mL}$ for SEM in buffer.

\section{Introduction}

Nitrofurazone(NFT) is an antibacterial agent and used as a veterinary medicine in the Livestock and poultry breeding, particularly in aquacluture.NTF is one kind of nitrofurans and Semicarbazide (SEM) is NTF's metabolite which can residue in animal tissues in a long time. SEM residue in the consumed animal tissues raising potential risks of the development of drug-resistance and chronic adverse effects in the public health. The maximum residues limits (RLs) of SEM in the food products of animal origin have been established in European Union. However, SEM-related fishery product-involved incidents often occur and have been a serious concern to human health. Therefore, the careful monitoring of SEM residue in fishery products for human consumption by sensitive methods is crucial for food safety and human health.

At present, many chemical analytical techniques have been established for analyzing SEM in samples, such as high performance liquid chromatography(HPLC), high performance liquid chromatographic tandem mass spectrometry(HPLC-MS/MS), electrochemical liquid chromatogramphy and enzyme-linked immunosorbent assay(ELISA). However, they all have some limitations in term of time-consuming and require extensive sample cleanup.

Antibody-antigen reaction were reported to analyze chloramphenicol, enrofloxacin , ciprofloxacin,and tetrodotoxin, it has advantages in cheaper cost and less operation step which make them particularly useful in routine work. As compared with other methods for SEM detection, fewer studies about immunoassays have been made, this mainly due to the lack of the specific antibody with high titer against SEM, which can support rapid immunoassay methods of SEM.

In the present study, we prepared polyclonal antibodies against SEM and try to establish an immunoassay method for SEM detection.

\section{Experimental}

\section{Reagents and materials}

Semicarbazide (Content $\geq 98.5 \%$ ) was purchased from Dr.Ehrenstorfer. Bovine serum albumin (BSA), ovalbumin (OVA), tetramethylbenzidine (TMB) and Peroxidase Horseradish (HRP) were obtained from Dingguo biotechnology Co. Ltd. 1-Ethl-3carbodiimide methiodide (EDC, purity $\geq 99.3 \%$ ) was obtained from Shanghai Yanchang biochemical technology Co., Ltd. Balb/c mice 
were from The Second Military Medical University. Chemical reagents such as $\mathrm{NaCl} 、 \mathrm{KCl}$, and $\mathrm{K}_{2} \mathrm{HPO}_{4}$ were from Shanghai Guoyao chemical reagent Co.Ltd.

\section{Methods}

\section{Coupling of the semicarbazide hapten and carrier protein}

The conjugate of SEM-BSA was synthesized by a modified carbodiimide method. $1 \mathrm{~mL}$ of SEM (20mg/mL in $0.01 \mathrm{M}$ PBS, $\mathrm{pH} 7.6)$ was mixed with $1 \mathrm{~mL}$ of BSA (32 mg/mL in $0.01 \mathrm{M}$ PBS, $\mathrm{pH} 7.6)$ and $1 \mathrm{~mL}$ of EDC ( $480 \mathrm{mg} / \mathrm{mL}$ in $0.01 \mathrm{M}$ PBS, pH7.6). Then $1 \mathrm{~mL}$ of PBS (0.01M, pH 7.6) was added, and the reaction was carried out in the buffer and incubated at $28^{\circ} \mathrm{C}$ for 2 hours. The mixture was dialyzed for 2 days in PBS ( $\mathrm{pH} 7.6$ ), and the dialyzing buffer was changed every day. After freeze-drying, the conjugate SEM-BSA was obtained and stored at $-20^{\circ} \mathrm{C}$.

The conjugate of SEM-OVA was synthesized by a modified carbodiimide method. $1 \mathrm{~mL}$ of SEM (20mg/mL in $0.01 \mathrm{M}$ PBS, pH 7.6) was mixed with $1 \mathrm{~mL}$ of OVA $(20 \mathrm{mg} / \mathrm{mL}$ in $0.01 \mathrm{M} \mathrm{PBS}, \mathrm{pH} 7.6)$ and $1 \mathrm{~mL}$ of EDC $(480 \mathrm{mg} / \mathrm{mL}$ in $0.01 \mathrm{M}$ PBS, pH7.6). Then $1 \mathrm{~mL}$ of PBS (0.01M, pH 7.6) was added, and the reaction was carried out in the buffer and incubated at $28^{\circ} \mathrm{C}$ for 2 hours. The mixture was dialyzed for 2 days in PBS ( $\mathrm{pH}$ 7.6), and the dialyzing buffer was changed every day. After freeze-drying, the conjugate SEM-BSA was obtained and stored at $-20^{\circ} \mathrm{C}$.

\section{Ultraviolet spectrum analysis}

SEM-BSA conjugate was scanned by Thermo Spectronic ultraviolet spectrophoto- meter, and the range of scanning wavelength from $220 \mathrm{~nm}$ to $320 \mathrm{~nm}$. Scanning step of the obtained spectrograms was $1 \mathrm{~nm}$ at scanning speed of $1 \mathrm{~nm} / \mathrm{s}^{-1}$.

\section{Generation of polyclonal antibody}

$150 \mu \mathrm{g}$ SEM-BSA conjugates and freund's complete adjuvant were mixed in the ratio of 1:1 to immunize the Balb/c mouse. Intraperitoneal injection was used for the first time. After two weeks, 150 $\mu \mathrm{g}$ SEM-BSA conjugate and freund's incomplete adjuvant were mixed in the ratio of 1:1 to perform a intraperitoneal injection to the mouse. One week later, the Balb/c mouse was immunized again in the same way. After 10 days, a part of the blood sample was collected to determine the antisera titer by ELISA, and then $150 \mu \mathrm{g}$ SEM-BSA conjugate was injected into the Balb/c mouse by tail intravenous injection. Three days later, the blood sample of the Balb/c mouse was collected, and then kept at $4{ }^{\circ} \mathrm{C}$ over night. The sample was centrifuged at the speed of $7000 \mathrm{rpm}$ for $10 \mathrm{~min}$, and then the supernetant was collected to determine the titer, and then freezingly stored for the future application.

\section{ELISA process}

$100 \mu 1$ SEM-OVA (prepared in our lab) with the concentration of $400 \mathrm{ng} / \mathrm{ml}$ was coated on the ELISA enzyme label plate and incubated at $37^{\circ} \mathrm{C}$ for $1 \mathrm{~h}$. After the enzyme label plate was coated, it was washed by $0.5 \%$ tween 20 phosphate buffer (washing solution) for 3 times, and for each time it was washed for $3 \mathrm{~min}$. The enzyme label plate was blocked by $200 \mu 15 \%$ milk solution and then placed at $4{ }^{\circ} \mathrm{C}$ over night. After that, $100 \mu$ antibody(antisera) was added to the enzyme label plate, and then incubated for $1 \mathrm{~h}$ at $37{ }^{\circ} \mathrm{C}$. After washed by the washing solution, $100 \mu \mathrm{l}$ Goat anti-mouse IgG/HRP (1:6000) was added and then incubated for $0.5 \mathrm{~h}$ at $37^{\circ} \mathrm{C}$. After the enzyme label plate was washed for 3 times, and then $100 \mu \mathrm{TMB} / \mathrm{H}_{2} \mathrm{O}_{2}$ solution was added in. 8 min later, $50 \mu \mathrm{l}$ of $2 \mathrm{M} \mathrm{H}_{2} \mathrm{SO}_{4}$ was added to stop the reaction. The absorbance of the enzyme plate was determined at $450 \mathrm{~nm}$ by the enzyme-labeling instrument.

\section{Detection of the sensitivity of antisera by indirect competitive ELISA}

The procedure of indirect competitive ELISA was similar to that mentioned in ELISA process with some modifications. Briefly, after block process, $50 \mu \mathrm{l}$ of suitable diluent antisera were added to each well and then $50 \mu \mathrm{l}$ of serial concentrations $(10,8,6,4,2 \mathrm{ng} / \mathrm{ml})$ of SEM solution were added and The subsequent steps were as described in ELISA process. 


\section{Results}

\section{Ultraviolet spectrum analysis}

The maximum absorption peaks of BSA, SEM and the SEM-BSA conjugate were at 279, 242 and $253 \mathrm{~nm}$, respectively(Fig. 1). The maximum absorption peak of SEM-BSA was different from BSA and SEM which indicated the success of synthesis. The successful coupling reaction between SEM and BSA could be speculated according to the methods of Yang (Yang, Hu \& wei, 1998), the molecular conjugate ratio of SEM to BSA was 32. SEM-OVA was also analyzed by the UV scanning spectrums method, and we found that the molecular conjugate ratio of SEM to OVA was 18, so SEM-OVA could be used in ELISA assay.

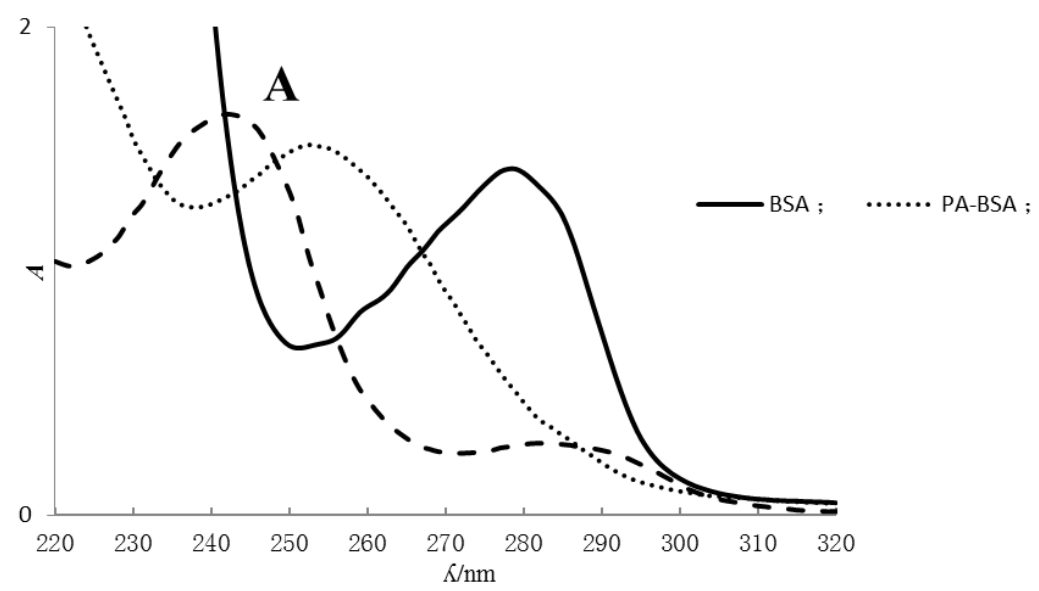

Fig.1 UV scanning spectrums of the conjugates

\section{The results of ELISA}

In the ELISA reaction, the titer was confirmed by the double value of the negative control. To immunize six mouse mice with the conjugates of SEM-BAS, the polyclonal antibody titer was determined by ELISA titer determination method, and the higst titer of polyclonal antibody could reach $10^{5}$.

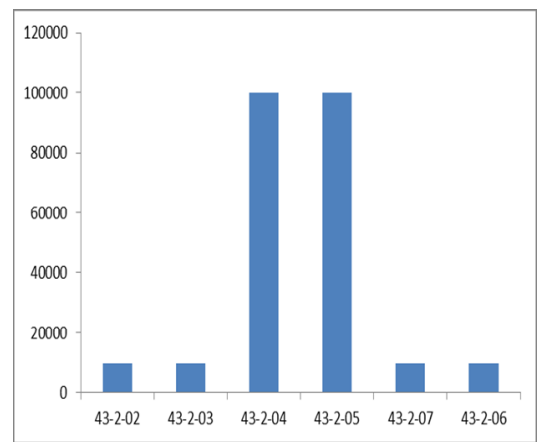

Fig.2 The titer of polyclonal antibody in different mouse

\section{Qualitative analysis of the polyclonal antibody}

The sensitivity of the antibody produced by the coupling reaction was determined by the ELISA method. The standard dilution curve analysis of the antibody prepared by the SEM-BAS exhibited its good sensitivity, which could achieve in the $\mathrm{ng} / \mathrm{ml}$ level. The $\mathrm{IC}_{50}$ was obtained by the optimized ELISA with the value of $25.0 \mathrm{ng} / \mathrm{ml}$.

\section{Discussion}

SEM which (molecular weight $<1000$ ) is usually not immunogenic by itself,but when the hapten is coupled with a macromolecule carrier, such as protein, peptide or synthetic amino acid. The hapten is generally coupled to the carrier protein through the epsilon amino group. The carrier protein can efficiently increase both the strength and the specificity of the antibody response. The coupling ratio of 
the hapten-protein usually effects the properties of the antibody which is induced by the modified hapten. Generally, the increase of the coupling ratio can enhance the strength and specificity of the immune responses for most cases.

Several synthesis methods of hapten with carrier protein have been reported, such as Mixed anhydride, Carbodiimide method, Glutaraldehyde method. However, few researches were reported about the conjugate of SEM-protein by Carbodiimide method which does not add the $\mathrm{N}$-Hydroxysuccinimide. The polyclonal antibody produced also directly confirmed that the method of conjugating SEM with carrier protein was successful.

\section{Conclusion}

In conclusion, we have prepared a sensitive, specific monoclonal antibody against SEM, and it is useful for analyzing SEM residues in food animal edible tissues through Ci-ELISA.

\section{References}

[1] J. Barbosa, S. Moura and R. Barbosa. Analytica Chimica Acta. Vol.586, (2007), p.359-365.

[2] M.Hernandez, C.Aguilar and F.Borrull, J. Chromatogr B. Vol. 772(2002), 163-172.

[3] P. Mottier, S.P. Khong and E. Germaug. Journal of Chromatograph A. Vol.1067, (2005), p.85.

[3] J.H.Duan and Z.H.Yuan. J. Agric.Food Chem. Vol.49(2001), 1087-1089.

[4] M.Fuentes, J .M.Palomo and C.Mateo. J. Immunol. Methods, Vol.307,144-149.

[5] A.F.S.A Habeeb. Arch. Biochem. Biophy. Vol.121(1967),652-664.

[6] I. Dibikova, K.M. Cooper and D.G. Kennedy. Analytica Chimica Acta. Vol.51, (2005), p. 285.

[7] M.P Marco, S.Gee and B. D.Hammock. Trac-trend. Anal. Chem, Vol.14(1995), 415-425.

[8] K.V.Singh, J.Kaur and C.V.Grish. Bioconjugate Chem, Vol.15(2004), 168-173.

[9] S.Pauillac, J.Naar and M.Barbara. J. Immunol. Methods. 263(2002),75- 83.

[10] Y.Zhou, Y.S.Li and Z.Wang. Chin. J. Vet. Sci. Vol.26(2006), 200-203.

[11] A.F.S.A.Habeeb. Anal Biochem. Vol.14(1966),328-336.

[12] J. Barbosa, S. Moura and R. Barbosa. Analytica Chimica Acta. Vol.586, (2007), p.359-365.

[13] P. Mottier, S.P. Khong and E. Germaug. Journal of Chromatograph A. Vol.1067, (2005), p.85. 